\title{
Redes Tecno-Econômicas e a Gestão da Inovação Tecnológica em Institutos de PesquisaTecnológica: Um Estudo de Caso no CEPEL
}

\author{
Francisco José Batista de Sousa \\ José Manoel Carvalho de Mello \\ Area de Inovação Tecnológica e Organização Industrial \\ Programa de Engenharia de Produção - COPPE/UFRJ - Rio de Janeiro - Brasil \\ CP 68.507 - CEP 21945-970
}

\begin{abstract}
Resumo
Este trabalho explora a questão da gestão da inovação tecnológica num instituto tecnológico, o CEPEL - Centro de Pesquisas de Energia Elétrica, tendo como referência as tecnologias ai desenvolvidas associadas ao campo dos medidores eletrônicos de consumo de energia elétrica. Apoiado por um estudo de caso abarcando a análise de todos os projetos tecnológicos desenvolvidos no período de 1980 a 1997 no CEPEL, através do conceito de Redes Tecno-econômicas, analisa o desempenho do CEPEL em levar tais tecnologias ao mercado.
\end{abstract}

Palavras-chave: inovação tecnológica; transferência de tecnologia; gestão da tecnologia; institutos tecnológicos; redes tecno-econômicas.

\begin{abstract}
This paper explores the technological innovation management in a Brazilian technological research center (CEPEL) in electric energy, referred to the electronic meter technologies to bill electric energy. The data are based on a case study including the analysis of all the technological projects developed in a time period of 18 years (1980-1997), using Techno-economic Networks as a conceptual approach to evaluate CEPEL's technological innovation performance.
\end{abstract}

Keywords: technological innovation; technology transfer; management of technology; technological labs; techno-economics networks

\section{Introdução}

Esse trabalho analisa o desempenho do CEPEL Centro de Pesquisas de Energia Elétrica - na gestão dos processos de inovação, referenciados às tecnologias associadas à medição eletrônica do consumo de energia elétrica, tendo como quadro referencial teóricometodológico o conceito de Redes Tecno-econômicas (Callon, 1992), através do qual o CEPEL é visto como um ator desenvolvendo redes de modo a dar sustentabilidade ao desenvolvimento e difusão de suas tecnologias.

Inicialmente é apresentado uma breve discussão de como o CEPEL ao longo do tempo percebe o processo de inovação e o gere, tendo como referência seus esforços para a inovação no campo das medições eletrônicas.

Na sessão seguinte as características gerais do conceito de Redes Tecno-econônicas são expostas e o entendimento mais amplo dos "sucessos" e dos "insucessos", no que tange a inovação, é apreciado a luz deste conceito.

Tendo como base empírica as informações detalhadas de todos os projetos tecnológicos (e da gestão dos mesmos) na campo das medições eletrônicas (medições horosazonais, para consumidores residenciais, e ampèrehora, para consumidores de baixa renda), desenvolvidos pelo CEPEL desde fins da década de 70, coletados através 
PRODUÇÃO

de entrevistas semi-abertas com os pesquisadores e gerentes do CEPEL, e do acesso à documentação existente. (Sousa, 1997), o desempenho inovador do CEPEL quanto a essas tecnologias é objeto de uma aprofundada discussão, a partir da ótica do CEPEL enquanto um ator construindo redes.

O trabalho finaliza com recomendações para a gestão da inovação por parte do CEPEL para o campo de medição eletrônica, generalizáveis para outras áreas e com uma discussão mais ampla sobre a questão da inovação e sobre outras possíveis alternativas de atuação em institutos de pesquisa tecnológica.

\section{A Questão da Inovação no CEPEL}

Criado em 1974, o CEPEL investiu muito na constituição e no aperfeiçoamento de seus pesquisadores. A facilidade advinda da proximidade com a universidade o CEPEL está instalado no campus da UFRJ - Universidade Federal do Rio de Janeiro - permitiu um grande entrosamento com os pesquisadores da UFRJ, fato que, aliado a uma política de aperfeiçoamento de seus pesquisadores no exterior, permitiu uma acelerada capacitação técnica do seu quadro.

Predominava no CEPEL, nesta sua fase inicial, o espirito acadêmico, com seus pesquisadores definindo suas agendas de pesquisa à semelhança dos pesquisadores universitários. A própria estrutura organizacional do CEPEL era no estilo universitário, por áreas do conhecimento. Através de discussões com colegas em eventos científicos, da leitura de revistas internacionais, da atenção às sinalizações dos órgãos de fomento, assim como da percepção de lacunas técnicas e de carências tecnológicas no sistema elétrico brasileiro, os pesquisadores do CEPEL construíam suas agendas de pesquisa e definiam as tecnologias a serem por eles desenvolvidas.

Esperava-se que tais tecnologias, consideradas possuidoras de uma excelência técnica, seriam então requisitadas e utilizadas pelos potenciais interessados nelas, bastando chamar à atenção deles para a sua existência.
O processo de inovação era então percebido como um processo linear, constituídos de duas fases em seqüência, a primeira a do desenvolvimento da tecnologia e a segunda, a da difusão da tecnologia. Caberia ao CEPEL a responsabilidade para com a efetivação da primeira fase "invenção da tecnologia" -, e caberia aos interessados as démarches para a aquisição e utilização das mesmas “difusão da tecnologia"-.

No nosso estudo de caso, no campo de medidores eletrônicos, o CEPEL percebia os fabricantes de equipamentos para medição eletrônica da energia elétrica como sendo seus potenciais interessados e com eles mantinham contatos regulares e praticamente informais, via seus pesquisadores.

Durante toda a década de 80, assim o CEPEL atuou, investindo em formação de pessoal, desenvolvendo tecnologias, mantendo contatos regulares com as indústrias. Mas não desenvolveu relações regulares com as concessionárias, nem com órgãos públicos reguladores que poderiam influenciar o processo de difusão das novas tecnologias que estavam, então, sendo desenvolvidas . Ademais, não havia uma compreensão muito clara, por parte dos pesquisadores, da necessidade de se ter ampla proteção por patentes.

Esta situação prevaleceu até o final da década de 80, quando então o CEPEL, tendo em vista as mudanças que se anunciavam no cenário brasileiro, com a internacionalização da economia e com a privatização de empresas estatais, deu início aos estudos que culminaram com sua profunda restruturação, implementada em 1992, conforme detalhada em Erber et alli (1995). Na ocasião foi então instituído o Plano Estratégico Institucional, que contou na sua elaboração com o importante apoio da Faculdade de Economia e Administração da Universidade de São Paulo.

Visava-se, com esta reestruturação, dotar o CEPEL de meios para atuar numa visão mais completa do processo de inovação, percebendo-o como um todo, em toda a sua complexidade. Não mais como um processo linear de duas fases, mas como um único processo, sem fronteiras entre as duas fases, sem responsabilidades compartimentadas. 
Esperava-se do CEPEL uma postura mais voltada para o mercado, uma visão mais empresarial, em contraste com a postura anterior, que era uma visão mais acadêmica.

No caso dos medidores, esperava-se que, a partir desta postura empresarial, houvesse uma percepção mais clara do papel dos diversos atores institucionais envolvidos no processo de inovação, agora em toda a sua complexidade. Esperava-se um reconhecimento do importante papel desempenhado pelas concessionárias. São elas as responsáveis pelas encomendas às empresas fabricantes de medidores. São as concessionárias que detém o poder de decisão quanto ao estabelecimento de um mercado para os medidores.

Contava-se também com a percepção da importância dos órgãos reguladores, tanto o normalizador (o INMETRO - Instituto Nacional de Metrologia) como o definidor da política tarifária (o DNAEE - Departamento Nacional de Águas e Energia Elétrica).

Acordava-se também que o CEPEL deveria adquirir capacitação em termos de propriedade intelectual e industrial (contratos e patentes), para o estabelecimento formal de contrato de transferência de tecnologia e cessão de direitos; contrato para industrialização; acordo de confidencialidade; contrato de uso da tecnologia; contrato de pré-qualificação; contrato de qualificação; e contrato de autorização de fabricação.

Em suma, postulava-se que para inovar, ou seja, para desenvolver e difundir suas tecnologias no mercado, era necessário que o processo fosse pensado como um todo, encaminhado através de um constante dialogo com todos os atores pertinentes, sob a responsabilidade do CEPEL, numa atuação em conjunto de pesquisadores e gestores.

Entretanto, esta visão integrada do processo da inovação, não conseguiu, na sua amplitude, ser efetivada no CEPEL. Certamente houve progressos, gestores foram capacitados para se encarregarem da difusão das tecnologias desenvolvidas no CEPEL, um escritório de transferência de tecnologia foi criado.

Embora uma nova estrutura organizacional tenha sido implementada, mais propicia à desejada mudança de rumos, não houve a necessária mudança de cultura, continuou ainda a prevalecer uma percepção inadequada do processo de inovação. A esperada ação conjunta dos pesquisadores com os gestores raramente ocorreu, principalmente na definição das tecnologias a serem desenvolvidas pelo CEPEL

Antes de situarmos as dificuldades existentes em inovar, exemplificando-as a partir de casos estudados no campo dos medidores eletrônicos, vamos vê-las através de uma perspectiva teórica a partir do conceito de Redes Tecno-econômicas.

\section{Redes Tecno-Econômicas}

Ultrapassando a versão simplista da trajetória de um objeto técnico como meramente resultante de suas características intrínsecas, de suas qualidades técnicas, temos o conceito de Redes Tecno-econômicas, que vê a trajetória como resultante de constantes negociações entre todos os atores envolvidos no desenvolvimento da mesma.

A trajetória de um objeto técnico não é algo preestabelecido, que segue o seu rumo indiferente a tudo e a todos. A trajetória deve ser vista como decorrente da rede tecno-econômica que lhe dá sustentação, ou seja, de um processo em permanente construção, através de um continuado processo de negociações, de um continuado alinhamento de interesses entre todos os atores envolvidos. $\mathrm{Se}$, em algum momento, estes interesses deixam de estarem alinhados, a rede se desestabiliza e a trajetória cessa.

Ao contrário do que se passa, por exemplo, em uma rede elétrica, onde lâmpadas não têm suas características mudadas pelo fato de pertencerem a uma dada rede ou estarem fora de redes, um mesmo ator pode assumir diferentes papeis estando dentro ou fora de uma rede tecno-econômica. Mais ainda, o papel que ele assume depende do conjunto dos papeis assumidos pelos demais atores e pelo papel desejado pelo ator construtor da rede tecno-econômica.

Manter os interesses de todos os atores alinhavados ao interesse do construtor da rede exige muita persuasão e 
PRODUÇÃO

convencimento por parte do ator construtor, numa tarefa continuada.

No nosso caso dos medidores eletrônicos, o CEPEL, em seus esforços para desenvolver e difundir suas tecnologias associadas aos seus equipamentos, pode ser percebido como um ator construindo sua rede tecnoeconômica, construindo-a para dar sustentação a trajetória por ele desejada para o seu objeto técnico. Para tal ele deve partir para enredar todos os atores que tenham, no seu entender, interesses em jogo no que se refere a trajetória desejada. Ou seja, ele deve buscar um continuado processo de negociações com estes atores, procurando permanentemente manter interesses alinhados com o seu. Caso haja hostilidade impossível de ser superada, por parte de um ou mais atores, interesses contrariados e incapazes de serem alinhados aos do CEPEL, a rede se desestabiliza, e a trajetória cessa.

O próprio objeto técnico é sujeito a negociações durante a construção da rede. Ele assume tal formato, tal especificação técnica, funcional ou estética em função também do conjunto de interesses em cena, em qualquer fase da construção da rede. Podemos dizer pois que tanto trajetórias como objetos técnicos têm sua definição dadas pelas redes que lhes dão sustentação.

Isso implica em que a própria concepção do objeto, a definição do mesmo, deve ser precedida por negociações entre os atores nele interessados, ele deve já encarnar uma demanda explicitada por pelo menos um ator que não o próprio construtor da rede.

No nosso caso, isto implica numa ação conjugada entre pesquisador e gestores, em busca de definir objetos técnicos factíveis mercadológica e tecnicamente, em serem sensíveis as demandas postas pelo mercado.

Por último cabe notar que qualquer ator para se manter a frente no processo de construção de uma rede tecno-econômica precisa possuir todos os recursos (pessoais, financeiros, etc.) necessários para tal, de forma permanente. Ele deve buscar ainda manter a legitimidade de seu papel - possuir poderes para tal - ao longo de todo o processo. Em suma, ele deve se constituir num chamado "ponto de passagem obrigatório" (Callon, 1986; apud Law, Cooper, 1995, pág. 257), o que lhe dará condição de manter a estabilidade de sua rede.

\section{O Desempenho do CEPEL: Inovações no Campo dos Medidores Eletrônicos}

\section{Décadas de 70 e 80}

A atuação no CEPEL, no campo dos medidores eletrônicos, em termos de inovação, isto é, no sentido de que uma tecnologia, aí desenvolvida, fosse transferida para empresas fabricantes, as quais passassem, com essa tecnologia, a produzir medidores em escala industrial, apresenta poucos e fortuitos casos de sucesso até o inicio da década dos noventa.

Durante este período os esforços do CEPEL estavam concentrados no desenvolvimento de tecnologias associadas a medição horosazonal para a Indústria, procurando estar em sintonia com as determinações emanadas então pelo governo federal .

Como vimos, prevalecia nas décadas de 70 e 80 uma visão linear do processo de inovação e o CEPEL passou a definir e desenvolver tais tecnologias sem maiores laços com os demais atores integrantes do cenário dos medidores eletrônicos. Em que pese o êxito obtido, o sucesso em desenvolvê-las, tais tecnologias não ultrapassaram os "muros" do CEPEL, elas não foram apropriadas e utilizadas pelos fabricantes de medidores eletrônicos.

Nesse contexto, casos de 'sucesso', no sentido de inovar, eram fortuitos, como o obtido na inserção no mercado de um Registrador Digital para Tarifação Diferenciada, que passou a ser produzido em $1983 \mathrm{em}$ escala industrial por empresas fabricantes com tecnologia desenvolvida e transferida pelo CEPEL.

Até meados da década de 80 a política energética tinha o governo federal como o ator praticamente hegemônico na sua condução - estávamos num regime militar. Com o retorno à normalidade democrática, outros atores institucionais passam a ter expressão na determina- 
ção da política energética, como, em particular, as concessionárias, no campo da definição dos medidores de consumo de energia elétrica.

As concessionárias, na ocasião, não estavam interessadas na ampliação do leque de tecnologias a serem usadas em medições horosazonais. Mesmo assim o CEPEL não alterou sua opção, continuou desenvolvendo tecnologias associadas à medição horosazonal, mesmo não havendo um cliente demandando, explicitamente, tais tecnologias.

$\mathrm{O}$ aparecimento de um quadro institucional com uma diversidade de atores com poderes decisórios - as concessionárias privatizadas -, torna a tarefa de se ajustar as sinalizações de oportunidades tecnológicas algo bem mais complexo. Esse novo quadro, conjugado com a visão linear do processo de inovação, tornava então mais rarefeita a possibilidade de 'sucesso', no sentido de inovar.

Em termos de redes tecno-econômicas cabe o seguinte comentário. Atuando na ótica de um processo linear de inovação, cabendo a si somente a construção de tecnologias, o CEPEL agia na verdade como um construtor de redes cujo objetivo residia precisamente na "invenção" destas tecnologias. Em termos de inovação, eram redes mais simples que as complexas redes que abarcam o processo de inovação na sua plenitude, mas, mesmo assim, cabe destacar toda a competência tida pelo CEPEL como construtor destas redes para invenção de tecnologias. Para chegar lá, foi necessário adquirir credibilidade científica, formar quadros competentes, sensibilizar órgãos de fomento a C\&T, nacionais e internacionais, assumir visibilidade em termos de publicação de artigos científicos etc.

\section{Década de 90}

A situação exposta acima começa a se alterar a partir do início dos anos 90, quando o CEPEL, como já vimos, passa a pautar a condução de sua gestão tecnológica por uma visão mais adequada do processo de inovação.

Embora passe a perceber a necessidade de conduzir as fases de desenvolvimento e difusão de tecnologias como um tecido sem costura, de forma unitária, a ausência de uma plena harmonia entre gestores e pesquisadores, por dificuldades internas, por visões e atitudes culturais diferenciadas, levou a que, na prática, o CEPEL tivesse que construir duas redes, de forma seqüencial, para concretizar a inovação. Uma primeira rede para o desenvolvimento e uma segunda rede para a difusão. A primeira conduzida basicamente pelos pesquisadores e a segunda pelos gestores.

Assim, por exemplo, no bojo de sua reforma administrativa no começo dos anos 90, é criado no CEPEL o Escritório de Transferência de Tecnologia e não propriamente um "Escritório de Inovação".

De qualquer maneira o CEPEL passou então, na década de 90, a atuar como um ator-construtor de redes, tendo como estratégia , em primeiro lugar, atrair diversas empresas que potencialmente poderiam se interessar pelas tecnologias referenciadas à horosazonalidade ai desenvolvidas, principalmente pelas tecnologias de Medição Horosazonal Residencial, Medição Centralizada e de Medição de Altas Correntes, associadas à medição para consumidores residenciais, edifícios e condomínios e grandes consumidores em baixa-tensão, respectivamente.

Para tal, passa a acionar um conjunto de mecanismos formais de transferência de tecnologia, estabelece com essas empresas acordos de confidencialidade, contratos de cooperação, contratos de avaliação de tecnologia, contratos de autorização para a instalação de um sistema piloto, contratos de pré-qualificação e contratos de qualificação.

O segundo passo nesta estratégia consistiria em sensibilizar as concessionárias para que elas criassem um mercado para tais tecnologias, ou seja, pela implementação de padrões de medições que viabilizassem a adoção desses medidores.

Na construção da rede através desta estratégia o CEPEL esbarra com uma dificuldade que se mostra intransponível: não conseguiu alinhar seus interesses com os das concessionárias. Elas não se mostraram interessadas 
PRODUÇÃO

nestas medições, nestes medidores. A rede se desestabilizou pelo não enredamento das concessionárias. Houve 'insucesso' no sentido de que o ciclo não foi completado, a inovação não aconteceu, não obstante ter havido a invenção e também ter havido a transferência, para as empresas, de conhecimentos e competências.

Não obstante suas limitações acima mencionadas, o escritório de Transferência de Tecnologia do CEPEL estva atento às sinalizações externas e, sempre que possível, buscava induzir seus pesquisadores para o desenvolvimento de tecnologias demandadas pelas concessionárias.

Porém, mesmo no caso em que a ação para a inovação passa a ser conduzida desde a definição da tecnologia a ser aí desenvolvida, em função de uma demanda tornada explícita pelas concessionárias, não foi possível ao CEPEL garantir a estabilidade da rede em construção, até a inovação tomar lugar.

Foi o que aconteceu com o caso de uma determinada tecnologia horosazonal aplicada a medidores residenciais. Em 1990, as concessionárias passaram a se interessar pela Medição Horosazonal Residencial, mas por meio de medidores individuais, o que implicaria na substituição dos existentes medidores convencionais.

Procurando sintonia com o interesse declarado das concessionárias, passa O CEPEL, a se dedicar ao desenvolvimento desta tecnologia, apresentando-a dois anos depois, em 1992.

Ao mesmo tempo, envolve nesta fase de desenvolvimento as empresas fabricantes de medidores e com elas assina contratos de transferência desta tecnologia, em 1993.

As concessionárias também, em comum acordo com o CEPEL - interesses alinhados - num passo a frente, visando a regulamentação da medição horosazonal residencial, e junto com o CEPEL, organizam, ainda em 1995, uma chamada para que as empresas que tenham medidores horosazonais aplicáveis à medição residencial, os apresentem para um teste.

A esta altura, a rede aparentava ter alcançado um regime de estabilidade, com todos os atores tendo seus interesses alinhados com os do CEPEL, na fase final de se

chegar a inovação. Porém ela se desestabiliza na medida em que uma mudança de interesses por parte dos fabricantes vem a tona e de forma inconciliável com os do CEPEL. Para os fabricantes, o interesse maior nesta fase última seria o de ganhar a concorrência e eles percebiam que teriam maiores chances apresentando medidores associados a tecnologias importadas ao invés da tecnologia de medição eletrônica desenvolvida pelo CEPEL. Assim o fizeram mesmo aqueles fabricantes que tinham adquirido a tecnologia desenvolvida pelo CEPEL. Isto se deveu, em grande parte, as facilidades advindas da diminuição de alíquotas de taxas de importação, oriundas da abertura econômica.

Estamos aqui diante de um novo e diferente caso de “insucesso", numa rede desestabilizada, retratando uma situação em que a existência de uma demanda explícita por parte de um ator institucional, com poder de criar o mercado para um dado equipamento de medição, e a existência de uma tecnologia desenvolvida pelo CEPEL e transferida para empresas, por si só não foram suficientes para garantir que essas empresas produzissem equipamentos usando essa tecnologia. Tenha-se em conta, que o CEPEL negociava a tecnologia e ainda uma remuneração percentual por produto vendido, o que caracteriza seu interesse na difusão tecnológica dos medidores com a sua tecnologia.

Os casos acima, assim como outros também documentados por Sousa, 1997, nos dão uma medida das dificuldades com que se defrontam Institutos Tecnológicos na atividade de inovar. Os casos por nós selecionados foram apresentados na ótica das redes tecno-econômicas para permitir percebê-los enquanto uma construção tecnoeconômica, para dar uma idéia de quanto investimento é necessário para se lograr uma inovação.

Na próxima seção, a da conclusão do trabalho, lidaremos com possíveis ensinamentos oriundos de nossa análise e com recomendações genéricas para a gestão de Institutos Tecnológicos. Para concluir a presente seção, apresentaremos de forma detalhada um último estudo de caso do CEPEL, onde uma inovação é alcançada, com vistas a expor toda a sua complexidade. 


\section{A complexidade da inovação - o caso do medidor ampère-hora}

O caso que passaremos a expor, na ótica das redes tecno-econômicas, se refere ao da tecnologia de medição ampère-hora para a medição do consumo de energia elétrica para consumidores de baixa renda, que teve curso no CEPEL, já na década de 90.

Conforme veremos a seguir, procurou o CEPEL identificar todos os atores institucionais relevantes ao processo e envolvê-los nas suas articulações, desde a definição da tecnologia a ser desenvolvida até a sua utilização no mercado. . A presença constante das concessionárias, das empresas, dos órgãos reguladores e normalizadores, enredados ao longo dos anos, legitima o projeto, dando-lhe sustentação. Ao alinhar a gestão para a inovação o CEPEL não se limitou a produzir artefatos e transferi-los à indústria. Negociou com as concessionárias , interagiu com a indústria, defendeu a nova tecnologia junto ao órgão regulador (DNAEE). O projeto dos medidores foi alterado em função das necessidades dos clientes (concessionárias) bem como, segundo as peculiaridades e dificuldades das empresas no processo de produção desses medidores. Foi projetado visando, entre outras situações, evitar as fraudes (engrenagens limadas, etc.), as desvantagens de uso (instalações sujeitas a danos, uso indevido e impróprias a locais de população de baixa-renda) e custo de instalações e medidores convencionais eletromecânicos.

O detalhamento de todo esse processo - a construção de uma rede tecno-econômica - é a seguir descrito, com o intuito de evidenciar toda a complexidade da gestão por parte do CEPEL, de um processo que visa a geração, transferência e inserção no mercado de uma nova tecnologia aí desenvolvida .

\subsection{Articulando a Rede}

O processo teve início no ano de 1992, quando das negociações entre as concessionárias do Norte e Nordeste
(CCON) do Sistema ELETROBRAS e o CEPEL, para o desenvolvimento de uma tecnologia que permitisse a cobrança de energia elétrica para os consumidores de baixa renda. Fruto dessas negociações o CEPEL teve assegurado o aporte de recursos necessários para a realização das atividades de $\mathrm{P} \& \mathrm{D}$.

Ainda na fase inicial do projeto, em 1993, houve o envolvimento de uma pequena empresa sediada no Nordeste. É estabelecido um contrato de pré-qualificação para fabricação do medidor ampère - hora . O CEPEL apoia a adequação desta empresa às isenções de impostos, concedidas à industria de medidores pelo Governo Federal. Isso permitiu dispor rapidamente de protótipos para as concessionárias localizadas no Norte - Nordeste, componentes do CCON, um ano após o desenvolvimento desta tecnologia.

O projeto começa a tomar corpo, a rede vai se articulando. Apesar da indiferença inicial por parte dos fabricantes tradicionais de medidores - localizados, principalmente, nas regiões Sul e Sudeste do pais -, assiste-se, em 1994, o interesse por parte de outros fabricantes pela absorção dessa tecnologia de medição em ampère-hora.

Ainda em 1994, esforços são feitos pelo CEPEL para viabilizar o registrador a ser usado no medidor Ampèrehora . Esse registrador, componente do medidor, necessário à leitura de consumo que permite o faturamento, obriga o CEPEL a ir ao Japão, com o intuito de envolver a matriz de um fabricante no Brasil como um aliado ao projeto. É, assim, assegurada a credibilidade, qualidade e custos menores para o artefato Medidor Ampère-hora.

Nessa fase inicial do projeto, da articulação da rede, O CEPEL se mantém na posição de um "ponto de passagem obrigatório". Superando adversidade, impõe, em 1994, um espaço amplo de negociações, deposita as patentes junto ao INPI - Instituto Nacional de Propriedade Industrial -, coordena a transferência de tecnologia em um processo formal e interage com o mercado - concessionárias estaduais, em sua maioria, obtendo destas o feed-back 
necessário ao aprimoramento da tecnologia de medição ampère-hora para consumidores de baixa renda.

\subsection{Enfrentando Instabilidades na Rede}

A rede passa a enfrentar problemas de diversas ordens em 1995, pondo em risco o seu desenvolvimento. Em primeiro lugar, por motivos de ordem financeira, por falta de capital, por insegurança quanto ao retorno do capital a ser investido, diversas empresas anteriormente interessadas não chegam a firmar contratos de transferência de tecnologia com o CEPEL. Da mesma forma, diversas empresas rompem com os contratos previamente estabelecidos, a maioria não chegando a absorver a tecnologia, a não se capacitar para a produção. Apenas duas empresas chegam a fase de produção de protótipos; como uma delas teve problemas contratuais, a fabricação de protótipos fica restrita, em 1995, a apenas uma empresa - a mesma envolvida desde o início no processo.

Um outro problema surge em 1995 envolvendo essa mesma empresa. Um contrato de fornecimento firmado entre ela e uma concessionária do Nordeste (SAELPA) sofre descontinuidade. Essa, ao romper o contrato de fornecimento de 60.000 medidores com a empresa, retiralhe o mercado assegurado à produção. Mercado este que representava $60 \%$ do contrato de pré-qualificação firmado com o CEPEL e que iria garantir à mesma a consolidação de sua atuação neste novo mercado, com a nova tecnologia, recém absorvida. A alegação da concessionária era de que não havia disponibilidade orçamentária para o período.

Apesar destas dificuldades iniciais, as empresas concessionárias do Norte - Nordeste recebem protótipos e os testam em campo, iniciando sua utilização comercial. Os testes de campo são efetuados e após alguns pequenos ajustes os medidores são aprovados para uso.

\section{Concomitante, em 1995, o INMETRO - Instituto} Nacional de Metrologia, tem dificuldade de emitir um parecer visto que, por ser uma nova tecnologia, haveria necessidade de se ter uma normalização para o seu uso e também para o procedimento de teste. A normalização é, usualmente, elaborada com a participação dos interessados (concessionárias e empresas), a certificação a ser dada pelo órgão metrológico ainda não ocorrera.

Ao final do ano de 1995, a adversidade se faz presente, também, pelas dificuldades na tramitação do seu pedido de Exame Preliminar para a concessão de patente internacional do Medidor Ampère-hora, solicitado pelo CEPEL ao PCT- Patent Cooperation Treaty -, face a um primeiro parecer desfavorável emitido por esse órgão.

\subsection{Consolidando a Rede}

O ano de 1996 marca uma reversão do quadro instável apresentado no ano anterior. Em primeiro lugar, através de uma articulação do CEPEL com o Governo Federal, o DNAEE, e a ELETROBRAS, é emitido um Decreto-lei permitindo o faturamento de energia pelas concessionárias através da modalidade de medição ampère-hora, e, decorridos apenas dois meses, fica pronta a sua regulamentação pelo DNAEE.

Tal fato, conjugado com a difusão efetuada pela ELETROBRAS, no mês posterior, do cálculo do faturamento de energia com o uso da nova tarifa regulamentada, abre um amplo mercado para os medidores ampère-hora, atraindo o interesse de outras concessionárias do sistema ELETROBRAS - inclusive as localizadas nas regiões Sul e Sudeste -, assim como de empresas fabricantes de medidores.

A rede ressurge então envolvendo novos atores. Fortalece-se com o estabelecimento, por parte do CEPEL, junto a concessionárias do Sul e do Sudeste, de um plano de trabalho visando o teste e o cálculo adequado da tarifação de energia elétrica via ampère-hora. e com os contatos iniciais que passa a firmar com concessionárias de outros países ( México, Argentina, Colômbia e Índia) para o teste do seu medidor ampère-hora.

Ainda em 1996 o CEPEL, após contestar o parecer (Written Opinion) do PCT, através do INPI, obtém o parecer favorável à obtenção da Patente Internacional. Finalmente, 
em meados de 1997, 2 (dois) novos fabricantes assinam contratos de transferência de tecnologia com o CEPEL.

Estávamos, assim, diante de um caso de "sucesso" em uma rede estabilizada, retratando: uma demanda explícita por parte de atores governamentais e concessionárias e criando o mercado para o medidor, haver uma tecnologia desenvolvida pelo CEPEL e transferida a empresas, e a produção desses medidores em escala industrial.

\section{Conclusões e Recomendações}

Cabe ressaltar, inicialmente, que seria errôneo deduzir que na fase da "postura acadêmica" não havia interesse do CEPEL em que as tecnologias aí desenvolvidas fossem apropriadas e utilizadas pelas empresas fabricantes. Certamente que havia esse interesse, mas o pensamento prevalecente era de que cabia ao CEPEL a responsabilidade pela oferta da tecnologia e que a utilização da tecnologia ocorreria naturalmente, a partir das necessidades do mercado, numa perspectiva clássica do chamado "modelo linear de inovação".

Os inúmeros casos de "insucesso" levantados no nosso estudo aconteceram principalmente na fase em que a gestão tecnológica do CEPEL se pautava por essa "postura acadêmica", corroborando o fato de que essa visão linear do processo de inovação é inadequada para lidar com toda a complexidade inerente a comercialização da tecnologia.

Para lidar com essa complexidade, uma gestão se pautando pela "postura voltada ao mercado" torna-se mais eficaz, na medida em que há uma conjugação de esforços visando articular todos os principais atores institucionais envolvidos no processo, com o CEPEL assumindo o papel de um ponto de passagem obrigatório. Conforme vimos, o "sucesso" do importante projeto Medidor Ampère-hora ocorre justamente quando é essa a postura adotada pelo CEPEL.

Porém, conforme vimos, "insucessos" também ocorreram mesmo quando dessa "postura voltada para o mercado", atestando a complexidade do processo de completeza do ciclo - desenvolvimento de tecnologia, transferência de tecnologia e utilização da tecnologia em escala industrial. Foi justamente para trazer à tona essa complexidade é que analisamos o desempenho do CEPEL através da abordagem "ator-rede", ou seja, considerando a atuação do CEPEL enquanto um ator-construtor de redes.

Na linguagem dessa abordagem, "sucesso" retrata uma situação em que a rede em construção chega a um estágio de consolidação e "insucesso" se refere a uma situação em que a rede não chega a se consolidar, ou seja, quando é desestabilizada.

Nos casos por nós analisados no campo da medição horosazonal e ampère-hora, os "insucessos" aconteceram a despeito da rede ter alcançado o estágio da transferência de tecnologia para as empresas fabricantes de medidores. Esse nos parece ser um ponto importante que não tem merecido a devida atenção nos trabalhos sobre inovação. No estudo de caso pudemos constatar o interesse sempre presente das empresas fabricantes em se apropriar dos conhecimentos tecnológicos desenvolvidos pelo CEPEL, seja através de mecanismos formais (por exemplo, via contratos de transferência de tecnologia) ou, como num significativo número de casos, via mecanismos informais (por exemplo, através de troca de informações entre técnicos).

Os "insucessos" por nós anotados estavam relacionados a redes desestabilizadas seja pelo não enredamento das concessionárias (implicando na ausência de um mercado para os medidores) ou pelo não enredamento das empresas fabricantes para com a utilização, na produção de medidores em escala industrial, da tecnologia desenvolvida pelo CEPEL e transferida para essas empresas.

A dificuldade maior, nos parece, para o "sucesso" de um projeto tecnológico no campo das medições horosazonal e ampère-hora não estava no enredamento das concessionárias. O CEPEL, principalmente após seu engajamento com a gestão tecnológica "voltada para o mercado", tem sido muito hábil em suas articulações com as concessionárias e com os órgãos reguladores (INMETRO, DNAEE). A dificuldade maior reside no enredamento das empresas fabricantes, em assegurar que as mesmas produzam medidores em escala industri- 
PRODUÇÃO

al utilizando a tecnologia desenvolvida pelo CEPEL.

Nada impede que uma empresa fabricante mesmo após estar de posse de conhecimentos tecnológicos desenvolvidos pelo CEPEL (via transferência de tecnologia) opte em produzir medidores utilizando uma tecnologia desenvolvida por terceiros. Na verdade, não há nada de paradoxal nisso, são atitudes que podem ser explicadas pela mesma lógica empresarial, como uma forma de atuação correta para o mercado.

Como pode então o CEPEL induzir uma empresa fabricante a optar pela tecnologia por ele desenvolvida para a produção de medidores em escala industrial? Sem a pretensão de esgotar as facetas pertinentes a essa questão, apontamos dois aspectos que nos parecem ser importantes para esse processo de indução, de enredamento.

O primeiro aspecto diz respeito ao tipo de empresa mais factível de tal indução. Do nosso estudo de caso podemos dizer que, ainda que com cautela quanto a generalizações, as empresas de pequeno porte e sem tradição no campo da medição eletrônica se mostraram mais factíveis de serem enredadas que as empresas tradicionais e de grande porte.

$\mathrm{O}$ segundo aspecto se refere aos mecanismos utilizados na transferência de tecnologia para as empresas fabricantes. Acreditamos que o aprimoramento desses mecanismos - incluindo toda a gama de contratos de transferência de tecnologia, licenciamento e patentes - e, mais ainda, o aprimoramento de uma expertise jurídica nessa área de atuação, possam em muito contribuir para melhor vincular a ação de transferência com a ação de indução.

A essas conclusões e recomendações extraídas a partir do nosso estudo de caso do desempenho do CEPEL no desenvolvimento e difusão de tecnologias associadas as medições horosazonais e ampère-hora, soma-se uma última, de caráter mais geral, a seguir apresentada.

É primordial que qualquer novo projeto tecnológico pressuponha um levantamento de todos os potenciais atores institucionais envolvidos no projeto, a análise dos interesses em jogo desses potenciais participantes, as dificuldades previstas para o enredamento desses atores, os mecanismos legais a serem utilizados e as possibilidades do CEPEL exercer a condução do processo de construção dessa rede, de alinhar interesses tão diversos, visando a completeza do ciclo - desenvolvimento de tecnologia, transferência de tecnologia e utilização dessa tecnologia na produção em escala industrial.

Encerramos nosso trabalho com um último comentário. Ao concentrarmos nosso estudo na análise do desempenho do CEPEL na condução de projetos tecnológicos não queremos implicar com isso que consideramos que essa seja a função principal do CEPEL. Nós não entramos no mérito dessa temática, não foi nosso objeto de estudo.

Permitimo-nos, no entanto, salientar que Rush et alli (1995 e 1996), analisando as funções exercidas por institutos tecnológicos tidos como de sucesso, mostram que esses institutos levam a cabo serviços e tarefas técnicas altamente especializados com os quais assistem a indústria em suas atividades inovadoras, numa variedade de modos. Segundo os autores, é nessa modesta arena que os institutos fazem sua mais efetiva contribuição aos sistemas nacionais de inovação nos quais eles estão situados.

Segundo ainda esses autores, são as atividades tecnologicamente "softs" e os serviços que complementam e difundem as atividades "hard" dos institutos tecnológicos de sucesso. As atividades "softs" - testes; auditorias técnicas; consultorias; seminários; treinamentos e em alguns casos certificação e padronização - são usadas para expandir o número de clientes e gerar retornos adicionais. Alguns desses institutos organizam consórcio de firmas para conduzir projetos aplicados de P\&D enquanto que outros levam a cabo projetos nacionais de grande escala. É dessa maneira que os institutos tecnológicos apoiam e melhoram suas infra-estruturas nacionais em C\&T.

Tais considerações apontam para a necessidade dos institutos tecnológicos terem uma estratégia diversificada, serem capazes de identificar possíveis nichos e formas de atuação. 


\section{Notas}

1 Os autores agradecem o apoio recebido do PGCT/ PADCT e do CNPq para a realização deste trabalho.

2 O CEPEL foi criado em 1974 pela

ELETROBRAS e suas empresas associadas, como uma sociedade civil sem fins lucrativos, tendo como objetivo ser um centro de pesquisas e desenvolvimento voltado a resolver os problemas peculiares ao sistema elétrico brasileiro.

3 O CEPEL vem desde fins da década de 70 desenvolvendo projetos tecnológicos em Medição Horosazonal e em Medição Ampère-hora (através do parâmetro Ah) tendo em vista, respectivamente, a medição do consumo de energia elétrica dentro e fora do horário de ponta (17:00 às 22:00) - a chamada tarifa amarela - e a medição do consumo de energia elétrica em consumidores de baixa renda (inicialmente $30 \mathrm{kWh}$, hoje considerados com o consumo até $140 \mathrm{kWh}$ ).

4 Excetuando-se o Laboratório de Equipamentos Elétricos, situado em Adrianápolis, Nova Iguaçu, Rio de Janeiro, destinado a ensaios de alta potência.

$5 \mathrm{~A}$ restruturação do CEPEL não acontece como um fenômeno isolado. A política científica e tecnológica no Brasil passou por uma profunda reformulação decorrentes da criação do Ministério da Ciência e Tecnologia, em 1985, e da nova orientação para a política econômica e da abertura do mercado doméstico em 1990. Passou-se a promover uma mais intensa e efetiva difusão das atividades de pesquisa como um instrumento de modernização da base industrial e da competitividade das firmas brasileiras. Diversos institutos tecnológicos públicos passaram por semelhantes processos de restruturação no início da década de 90 , com vistas a atuarem mais próximos ao setor produtivo (Maculan e Zouain, 1998; Maculan e Mello, 1997).

6 Este papel é agora desempenhado pela ANEEL Agência Nacional de Energia Elétrica, LEI N ${ }^{\circ} 9427$, de dezembro de 1996, com republicação determinada pelo art. 22 da LEI N 9648, de 27 de maio de 1998.

7 As instalações, em consumidores de baixa-renda, caracterizavam-se por ligações ilegais ("gambiarras") que além do risco ainda significavam uso incontrolado em razão da ausência de medição.

$8 \mathrm{CCON}$ - Comitê Coordenador de Operação do Nordeste.

9 O CEPEL, estimava-os em 1994, no Nordeste, em um milhão de consumidores sem medição e que "eram faturados pelo consumo mínimo o que normalmente não reflete o verdadeiro consumo" (ELETROBRAS - Plano Decenal 2000/2009).

10Vide, por exemplo, Gibbons et alli, 1994, p. 51.

11 Analisando o desempenho de institutos de pesquisa em países em processo de industrialização, Bell (1993) sublinha o fato de que muito desses institutos foram instalados por iniciativa dos governos, sob a forma de laboratórios centralizados com grandes missões de subsidiarem o desenvolvimento econômico, através da geração de ciência e tecnologia, numa perspectiva própria do modelo linear de inovação. Segundo ainda Bell e também Rush et alli (1995 e 1996), malogros resultaram a partir da visão equivocada de que esses institutos assim organizados poderiam ser um substituto para a $P \& D$ industrial e que poderiam gerar inovações para serem exploradas pela indústria local.

12Para um aprofundamento dessa questão vide Sousa, 1997.

\section{Referências Bibliográficas}

BELL, R.M. (1993), Integrating R\&D with Industrial Production and Technical Change: Strengthening Linkages and Changing Structures. Workshop on Integration of Science and Technology in the Development Planning and Management Process, United Nations Economic and Social Council, Economic and Social Commission for Western Asia, Amman-Jordon.

CALLON, M. (1992), The dynamics of Technoeconomic Networks. In Coombs, R.; Saviotti, P. e Walsh, V., (eds.) Technological Change and Company Strategies. London: Academic Press, pp. 72-102. 
CALLON, M.; LAW, J. (1989), On the Construction of Sociotechnical Networks: Content and Context

Revised, Knowledge and Society, vol. 9: pp. 57-83.

ELETROBRAS (1996), Ministério das Minas e Energia Resumo do Setor Elétrico Brasileiro - Res. 95.

ERBER, F.S., AMARAL, L.U. (1995), Os Centros de Pesquisa das Empresas Estatais: Um Estudo de Três Casos. In: Ciência e Tecnologia no Brasil: Política Industrial, Mercado de Trabalho e Instituições de Apoio (Schwartzman, S., (ed.), pag. 333-371, Fundação Getúlio Vargas, Rio de Janeiro.

GIBBONS, M.; LIMOGES, C.; NOWOTNY, H.; SCHWARTZMAN, S.; SCOTT, P.; TROW, M. (1994) The New Production of Knowledge: The Dynamics of Science and Research in Contemporary Societies. London: SAGE Publications

LAW, J.; Cooper, R. (1995), Organization: Distal and Proximal Views, research in the sociology of organizations, vol. 13, pp. 237-274, JAI Press Inc.Mello, J. M.C.; Neto, J. M.; Sousa, F.J.B. (1998), "Management of Technological Diffusion: A Case

Study in a Brazilian Public Technological Institute" in Mason, R.: Lefebvre, L; Khalil, T. (eds.), Abstract Book, Management of Technology, Sustainable Development and Eco-Efficiency, Seventh International Conference on Management of technology. Florida: IAMOT, 1998, p. 150.

MACULAN, A-M; ZOUAIN, D.M. (1998), "Changes in Brazilian Public R\&D Institutions Management: The National Institute of Technology Case-Study". A Triple Helix of University-Industry-Government Relations: The Future Location of research? Conference. Purchase College, State University of New York, January.
MACULAN, A.M., MELLO, J.M.C. (1997), "Mudanças no Sistema de Pesquisa e Inovação das Indústrias de infra-estrutura: A necessária redefinição do papel dos centros de P\&D das empresas públicas". Workshop PRONEX - NEI. Universidade Federal do Rio de Janeiro, 24-25, Julho.

RUSH, H., ARNOLD, E., BESSANT, J., MURRAY, R. (1996), Technology Institutes: Strategies for Best Practice International Thomson Business Press, London.

RUSH, H.; HOBDAY, M.; BESSANT, J.; ARNOLD, E. (1995), Strategies for best practice in research and technology institutes: an overview of a benchmarking exercise. R\&D Management, 25, pp.17-31.

SOUSA, F.J.B. (1997), Gestão da Difusão Tecnológica, um Estudo de Caso: CEPEL - Os Medidores Eletrônicos. Tese de Mestrado, COPPE/UFRJ, Março. 